\title{
Prevalence and Intensity of Hookworm Infections in Ekiti, Nigeria; A Cross Sectional Study in State Specialist Hospital and Federal Medical Centre
}

\author{
S. O Adewole and I. A. Akingbolu \\ University of Ado-Ekiti, Department of Zoology, Faculty of Science, P.M.B. 5363, Ado-Ekiti, Ekiti State, Nigeria.
}

\begin{abstract}
Prevalence of hookworm and other helminthes infections from year 2004 till May, 2007 was carried out in both the State Specialist Hospital and Federal Medical Centre, in Ekiti State. Of the 2,686 recorded and examined, 1,246 persons representing 46.3\% were infected with helminthes while 53.7\% were infected with other helminthes like Ascaris lumbricoides and Trichuris trichura. At State Specialist Hospital (Ado-Ekiti), 646 persons representing 47.1\% were infected with hookworm while 600 persons representing 45.5\% were infected with hookworm at Federal Medical Centre, (Ido-Ekiti). There is a significant difference $\left(\mathrm{X}^{2}=8.9 ; \mathrm{P}<0.05\right)$ in the prevalence and susceptibility of males and females to infections in the State Specialist hospital, Ado-Ekiti. Also, there is no significant difference $\left(\mathrm{X}^{2}=3.82 ; \mathrm{P}>0.05\right)$ in the prevalence and susceptibility of males and females to hookworm infections.
\end{abstract}

Key words: Prevalence, Epidemiology, Helminthes, Infections Hospital.

\section{Introduction}

Hookworm is an intestinal parasite of mammals; the most important at least from human stand point are the human hookworms: Ancylostoma duodenale and Necator americanus. Heavy infection with hookworm can create serious health problems for newborns, children, pregnant women and persons who are malnourished. (Haburchak, 2006). The hookworm eggs are transmitted by improper disposal of faeces or urine and agency of insect host (Adenusi and Ogunyomi, 2003). Thus the infection is endemic in areas where sanitation are poor, Knowledge of the disease and its prevention is minimal, where health education is often nonexistence especially in warm humid areas of the tropics and subtropics (Schad, 1991).

Contamination of soil through direct defecation or deposition of faeces on the ground, in other words poor sanitation, exposure of skin to infected soil for instance working barefooted and the use of human faeces for fertilizers. When the egg hatches, the infective thread-like larvae penetrate human skin (foot) and migrate to the small intestine, there they mature (Albonico et al, 2004).

The main clinical feature of hookworm infection is anaemia due to blood loss and the degree of blood loss has been related to the type of hookworm involved (Albonico et al, 2004). The blood loss was estimated as $0.03 \mathrm{ml}$ per worm per day in
$N$. americanus and $0.15 \mathrm{ml}$ per day in $A$. duodenale (Albonico et al, 2004). There might be no difference seen between genders that is more susceptible to hookworm infection in adult but clear difference is seen in school children (Ayorinde, 2004). Despite considerable advances in chemotherapy and control, hookworm rank amongst the most widely spread of soil-transmitted helminthes parasite and affect a significant proportion of the world population (Olsen, et al, 2006). The preliminary data based on a survey in the two hospitals estimated that $47 \%$ of hookworm infections were discovered in State Specialist Hospital while 46\% of helminthes infections were hookworm cases at Federal Medical Centre, Ido-Ekiti. Therefore, this study aimed at providing quantitative information on the prevalence, epidemiology and probable suggestion on the control measures of hookworm infections in this part of the world.

\section{Materials and Methods}

\section{The Study Area}

The study was carried out in Ekiti state located in the SouthWestern Nigeria. Ekiti State is located between longitude $4^{\mathrm{O}} 5^{1}$ and $5^{\mathrm{O}} 45^{1} \mathrm{E}$ and latitude $7^{\mathrm{O}} 15^{1}$ and $8^{\mathrm{O}} 5^{1} \mathrm{~N}$ Inhabitants living in the rural areas are manily farmers as well as petty traders with few migrant labourers.

\footnotetext{
* Corresponding author: E-mail: Samson_adewole@yahoo. Com.
} 


\section{Data Collection}

Before data collection, the consent of the management of both hospitals were sought and the approval to check their records and collate all cases relating to helminthes infections was given. Two thousand, one hundred and five $(2,105)$ was ecorded in their records while another five hundred and eighty-one were examined for stool samples to ascertain the procedure(s) earlier used to diagnose the stool samples collected from patients in the previous years before the commencement of this research work. In all, a total of 2,686 patients stool samples were used for this research work.

\section{Stool Collection and Examination}

Stool samples were collected form patients in a different specimen bottles. 1-2 g of the stool sample was taken from each of the different specimen bottles and fixed into $10 \mathrm{ml}$ of sodium-acetic acid formalin separately; this was later processed with ether and mounted on microscope slides. The slides were later observed under the binocular microscope.

The total number of patients infected with hookworm and other helminthes infections were ascertained. Descriptive statistics were employed to analyse results with respect to susceptibility of males and females to infections.

\section{Results and Discussion}

Of the 2,686 patients recorded and examined for helminthes, 1,246 representing $46.3 \%$ were infected with hookworm infections.

Figure 1 shows the prevalence of hookworm and other helminthes infection in State Specialist Hospital respectively. A total of three hundred and fifty-nine (359) males representing 55.5\% and 287 females representing 44.4\% were infected with hookworm from 2004 till May 2007. It is evident from Figure 2 that the total number of males infected with other helminthes (Ascaris lumbricoides and Trichuris trichura) was 399 representing 55.1\% while 325 females giving $44.8 \%$ of those infected with other helminthes in the hospital.

There was a balance of infection in year 2005 in which both the males and females nearly have the same number of infected patients with hookworm (Fig. 1). The highest percentage of males infected with hookworm was in year 2006 having $62.6 \%$ while the least percentage of $37.3 \%$ was found in females.

Figure 2 shows the prevalence of hookworm and other helminthes in Federal Medical Centre, Ido-Ekiti. Of the 600

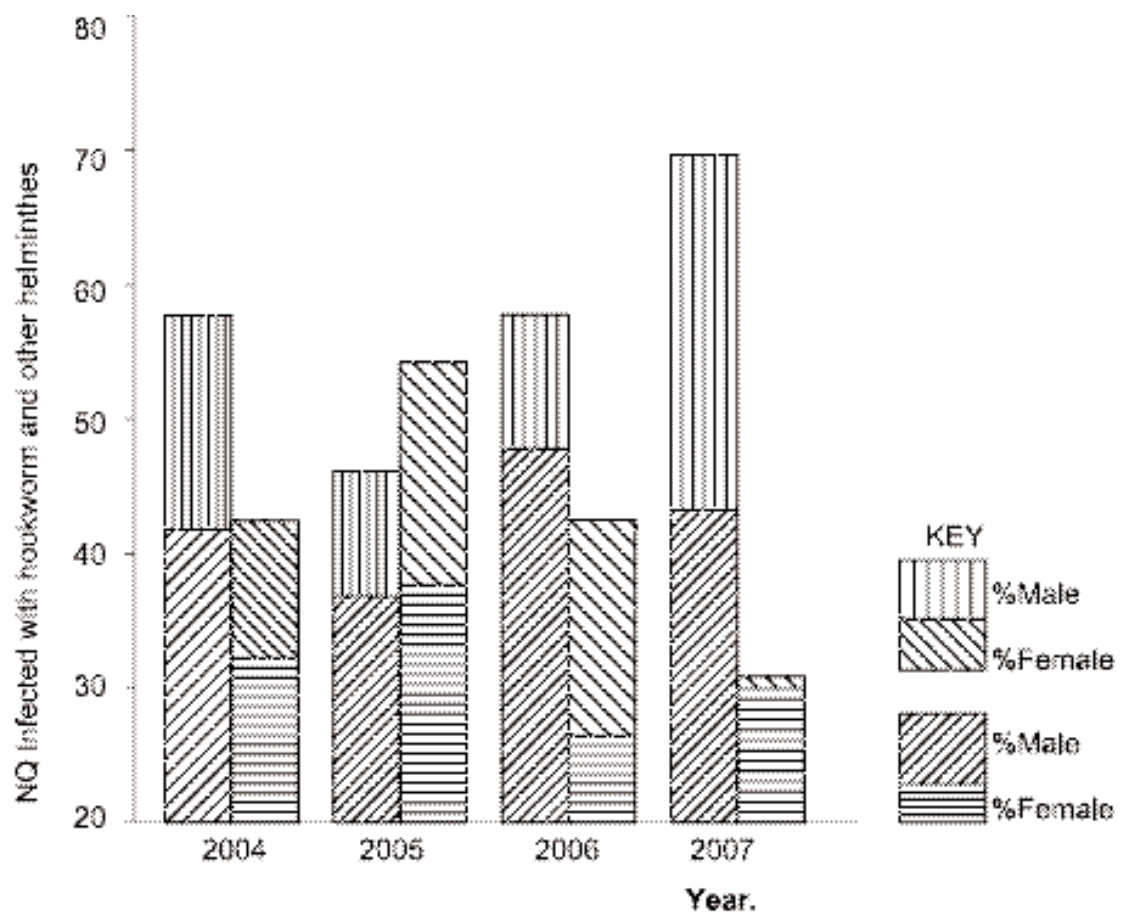

Fig. 1 . Prevalence of Hookworm and other Helminthes Infections at State Specialist Hospital 
persons infected with hookworm, 298 are males representing $49.6 \%$ while 302 are females representing $50.3 \%$. 716 persons were infected with other helminthes in which 490 (68.4\%) males and 226 (31.5\%) females were infected respectively.

It is evident from Figure 2 that females possessed higher percentages more than females in years 2004 and 2006, the number of patient infected with other helminthes recorded in Federal Medical Centre, Ido- Ekiti, shows that the percentage of males was completely higher than that of females in all the years with year 1004 producing the highest percentage of $78.6 \%$ for males and $21.3 \%$ for females. Also, in year 2007 with males having $71.8 \%$ and females have $28.1 \%$ (Fig. 2).

There is a significant difference $\left(\mathrm{X}^{2}=8.9\right.$; $\left.\mathrm{P}<0.05\right)$ in the prevalence and susceptibility of infections between males and females in the State Specialist Hospital. Also, there is no significant difference $\left(\mathrm{X}^{2}=3.82\right.$; $\left.\mathrm{P}>0.05\right)$ in the prevalence and susceptibility of males and females to hookworm infections.

Hookworm is known to be an indicator for environmental contamination with human wastes. The prevalence of hookworm and other helminthes infection in Ekiti State, decrease and the yearly decrease may be attributed to the fact that there is improvement in health care facilities, improved standard of sanitation and increasing publicity and awareness on the mode of transmission of hookworm infections (Rochie and Layrisse, 2002).

Records and examined patients from both hospitals show light and severe infections, an indication that some patients harbour more hookworms than others (Haburchak, 2006). Also, the variations in the level of infections may be due to the fact that the severity of hookworm pathology is directly related to the number of hookworm harboured by an individual (Albonico et al, 2004). Overcrowded living conditions increase the likelihood of fecal-oral transmission. The intensity of infection is influenced by hygiene, environmental and socioeconomic factors (Rochie and Layrisse, 2002). In hookworm and other helminthes endemic areas of Ekiti State particularly where the hospitals are located, the inhabitants have low income hence poverty and consequently low socioeconomic status. Low socioeconomic status is a factor for poor hygiene and parasitic infections (W.H.O., 2003).

Therer is no significant difference in the prevalence and susceptibility to infections between the sexes and there is a sharp increase in the number of a patients infected in 2005 compared to other years in Federal Medical Centre, reasons might be that people were more exposed to the risk of being infected by walking barefooted on infected soil. People are equally exposed to hookworm infection, both sexes and all ages are susceptible but males were found with higher infection than female for young children which may be due to

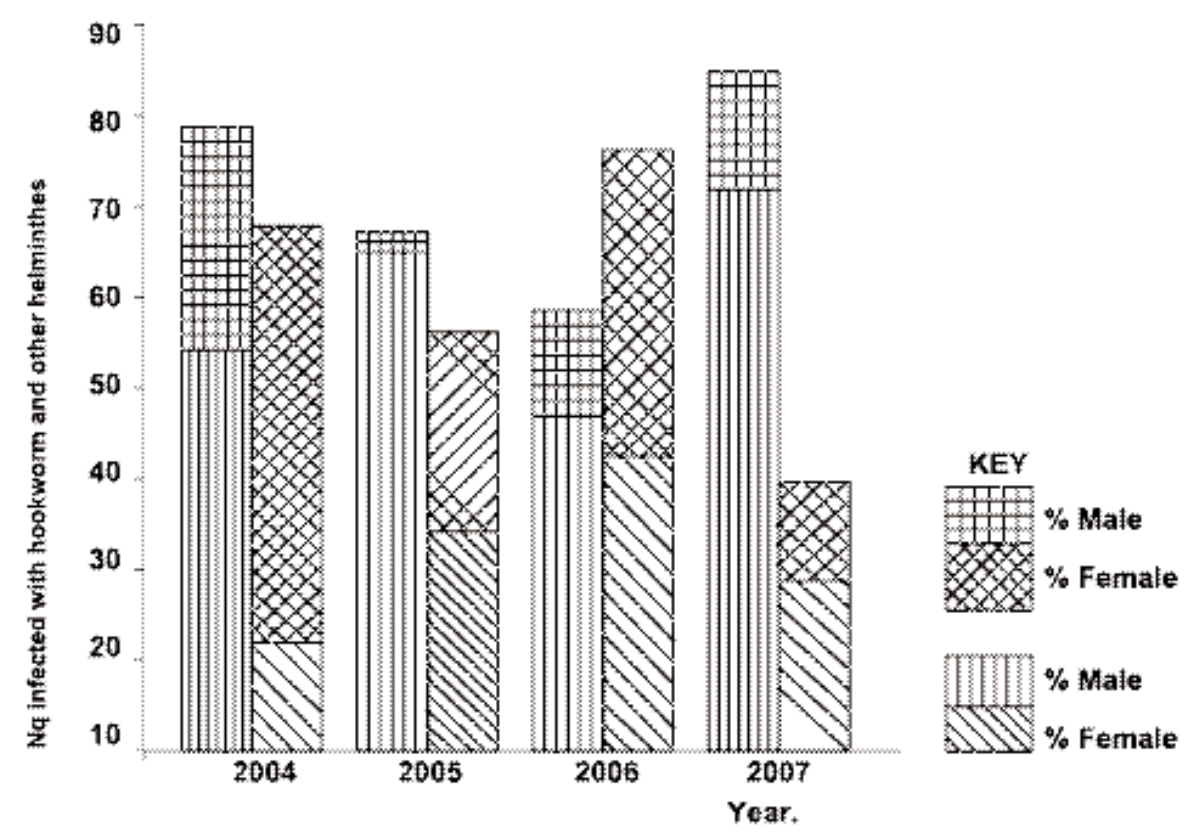

Fig. 2 . Prevalence of Hookworm and other Helminthes Infections at Federal Medical Centre 
frequent exposure to infected soil and played around the contaminated ground they infect their hands/fingers with infective ova of helminthes which are transferred to the mouth, especially when they fail to wash their hands before eating. This tallies with the work of Ayorinde, (2004) that worked on prevalence and intensity of helminthes in school children. In the case of adults, males are found with higher rate of infections because males are directly involved in farm work like cutting and cleaning of bushes, tilling and planting while females are only introduced at harvesting with their bare feet on already contaminated soil.

The Statement that hookworm infection is found to be cosmopolitan but most prevalent in tropics and subtropics (Hsieh, 2001) agrees with this research work because Ekiti State (developing State) is located in the tropical region where very few people use good sewage disposal system and majority practice farming in the rural areas, where hygiene is low.

\section{References}

Adenusi A. and Ogunyomi E. (2003) Relative prevalence of human Hookworm, Necator americanus and Aneylostoma duodenale in urban community in Ogun state. Afri J. of Biotech. 2: 470-473.

Albonico M., Stoltzfus R. , Savioli L. and Tielsch J. (2004) The epidemiology of hookworm infection and its contribution to anaemia among pre-school children on the Kenya coast. Pub. Med J. 80: 240-246.
Ayorinde T. A (2004) Studies on the prevalence and intensity of Nematodiasiss in school children in Ado-Ekiti. Excell. Pub. 20: 5-17.

Haburachak D. (2006) Hookworm of man Hlth. link. pub. 3: 437-440.

Hsieh H. C. (2001) Diagnosis of Anoylostoma duodenale, Necator americanus and Strongyloides stercoralis. Mlmeog annex. 1: 37-41

Olsen A., Magnussen P., Ouma J. and Friss H. (2006) The contribution of hookworm and other parasitic infection to haemoglobin and adults in Iron status among children and adults in Western Kenya. Trans. R. Soc Hyg. 11: 643-649.

Rochie D. and Layrisse G. (2002) Epidemiology of hookworm infection in Itagua, Paraguay. A South Am. J on Med 5: 48-54.

Schad G. A. (1991) Hookworm in tropical and Geographical medicine. Published by New York MC Craw hill 212213pp.

World Health Organisation (W.H.O) (2003) Guidelines for the evaluation of soil Transmitted helminthiasis at community level. Div. Trop Dise. 4: 98-105.

Received : September 07, 2008;

Accepted : February 11, 2009 